\title{
Higher Maternal and Child Undernutrition in Pulse than Cereal Growing Rural Communities of Ethiopia: A comparative Cross-sectional Study
}

\author{
Getahun Ersino $^{1,2}$, Carol J. Henry ${ }^{1}$ \& Gordon A. Zello ${ }^{1}$ \\ ${ }^{1}$ College of Pharmacy and Nutrition, Division of Nutrition and Dietetics, University of Saskatchewan, Saskatoon, \\ Canada \\ ${ }^{2}$ School of Nutrition, Food Science and Technology, Hawassa University, Hawassa, Ethiopia \\ Correspondence: Getahun Ersino, College of Pharmacy and Nutrition, Health Science E-wing, University of \\ Saskatchewan, 104 Clinic Place, Saskatoon, SK, S7N 2Z4. Canada. Tel: 1-306-966-1151. E-mail: \\ getahun.lombamo@usask.ca
}

Received: January 4, 2019

Accepted: January 25, 2019 Online Published: March 7, 2019

doi:10.5539/jfr.v8n2p100

URL: https://doi.org/10.5539/jfr.v8n2p100

\begin{abstract}
Background: Whether growing pulses (low fat legumes rich in protein and micronutrients) translates to nutritional health benefits has not been well documented in Ethiopia. In pulse- and cereal-based agricultural communities, we compared the nutrition of mothers and children $(<5 \mathrm{y})$ through anthropometric and dietary assessment to document evidence of pulse agriculture translating to nutritional health benefits. We also explored contextual factors influencing nutritional status.
\end{abstract}

Methods: Comparative study was conducted in purposively selected pulse- and cereal-growing Ethiopian communities, from rural Halaba and Zeway, with randomly selected individual participants of 413 and 217 mother-child dyads, respectively. Dietary diversity scores (DDS) and consumption indexes for selected food groups were assessed; median intakes of energy, protein, Fe, Zn, Ca were determined from a single-day weighed food records (in a subsample). Mother-child undernutrition was estimated using anthropometric assessments of weight, length/height and mid-upper-arm-circumference, MUAC.

Results: Median energy and nutrient intakes for pulse-mothers, but not children, were significantly higher than cereal-mothers $(p<0.01)$; Median DDS for mothers-children were three, out of nine food groups, in both communities; consumption index of pulses, although higher in the pulse-community $(p<0.001)$, was generally low amounting to consumption of only 1-2/week; consumption from animal sources was minimal. Undernutrition in mothers was $22 \%$ in pulse and $14 \%$ in cereal. Child stunting, wasting and underweight were $53.5 \%, 10.4 \%$ and $36.5 \%$ in pulse and $41.8 \%, 4.1 \%$ and $21.6 \%$ in the cereal group, respectively. Gender-sensitive factors, such as access to own-land and work-burden predicted maternal-MUAC. Stunting, household size, land size, antenatal-clinic visits and frequency of dairy consumption also predicted maternal-MUAC. Child age, community (i.e., pulse- or cereal-growing), household size and land size predicted chid height-for-age z-score (HAZ). Pulses were mostly sold and women had limited control; mothers' knowledge of the nutrition benefits of pulses was lower in pulse community $(p<0.01)$.

Conclusions: Poor DDS, pulse or animal-source food consumption and high levels of maternal and child undernutrition were found in both communities. The unexpected finding of greater undernutrition in the pulse-growing Halaba communities was of concern needing further investigation. The pulse-community could benefit from educational nutrition-intervention focusing on nutrition and other benefits of pulses.

Keywords: pulse, cereal, rural communities, maternal and child undernutrition, Ethiopia

\section{Background}

The nutrition of women and children in rural Ethiopia continues to suffer from inadequacy as diets lack variety and desired energy and nutrient density. Studies in southern Ethiopia have reported low dietary diversity, higher micronutrient (iron \& zinc) deficiencies and limited consumption of animal source foods among women and young children (Abebe et al., 2008; Gebremedhin, Enquselassie, \& Umeta, 2011; Gibson et al., 2009; Gibson et 
al., 2008; Tessema, Belachew, \& Ersino, 2013). Given the similarities in socio-economic profiles, these poor dietary practices can be assumed to be characteristics of other parts of rural Ethiopia. The poor nutritional status of rural women and children in the past 15 years remained $45 \%$ to $72 \%$ higher compared with their urban counterparts (Central Statistics Authority [CSA], 2014; CSA \& ICF International, 2012; CSA and ORC Marco, 2006). One area to mitigate this situation can be by assessing and intervening to improve the dietary habits of the women and children.

Pulses (low fat legumes including dry beans, peas, chickpeas and lentils) are the second most important food crops in Ethiopia following cereal grains with potential to improve nutrition in resource poor settings. Pulses provide high protein compared to cereals and provide other micronutrients (Ofuya \& V., 2005; Pulse Canada, 2012, 2016). Compared to animal protein, pulses can be affordable protein and micronutrients sources, particularly in communities where animal protein is expensive. Pulses provide other benefits such as serving as source of cash-income, natural fertilizers and food security crops (International Food Policy Research Institute [IFPRI], 2010). Including pulses in the diet or using the income generated from pulse sales to procure nutritious foods can improve dietary diversity of individuals. Dietary diversity, i.e. consumption of a variety of foods from different food groups, is a proxy for diet quality and micronutrient intake of individuals (Kennedy, Ballard, \& Dop, 2011).

However, the benefits of growing pulses and its link to the nutrition of vulnerable populations in Ethiopia have not been well documented. Only one study was found that assessed the dietary intakes (including pulses consumption), dietary diversity and overall nutritional status of adolescent girls in traditionally pulse-growing communities in Ethiopia (Roba et al., 2015). Other studies from southern Ethiopia have documented improved knowledge, attitudes and behaviours in mothers, and improved dietary diversity and energy intakes in young children following a nutrition education promoting pulse-based complementary foods for young children (Kebebu, Whiting, Dahl, Henry, \& Abegaz, 2013; Mulualem, Henry, Berhanu, \& Whiting, 2016; Negash et al., 2014).

Although pulses provide multiple nutrition benefits, growing pulse crops may not necessarily mean more pulse consumption - households could choose to sell their pulse harvest for cash income instead. Likewise, not growing pulses may not necessarily mean less or no pulse consumption either-households could purchase their pulses from the market place. Evidence is limited to fill this gap in knowledge. This study was the first to compare dietary intakes, dietary diversity and overall nutritional status of mothers and children in pulse versus cereal growing communities. Considering the potential of pulses to improve nutrition and generate household income, the study hypothesized that mothers and children living in pulse-growing communities would be nutritionally better compared with mothers and children in a similar but mainly cereal-based community.

\section{Methods}

\subsection{Study Setting, Participants and Design}

The study was conducted in two rural locations in Ethiopia, two pulse-growing communities from the Halaba district and one cereal-growing (non-pulse) community from Adami-Tulu-Jido-Kombolcha (ATJK) districts, near Zeway town. The two districts (also known as Woredas) are in the Southern Nations, Nationalities and People's Region (SNNPR) and Oromiya Regional State, respectively. The selection of the study sites (pulse- or cereal-growing communities) was purposive as these areas were locations for a larger collaborative research-project between Hawassa University in Ethiopia and the University of Saskatchewan in Canada, of which the current study was a part. The specific communities in each district were selected in consultation with the local agricultural offices based on whether the communities were mainly pulse- or cereal-growing (i.e., whether most of the farming households grow one or more pulse crops or not). The purposive selection of the communities was only with respect to the type of crops grown and size of production, compared to other similar communities in the region. Thus, the selected communities, otherwise, share characteristics like other communities in their respective regions. For example, most rural communities in each district were served by similar government-led basic health and agriculture infrastructure (via the health and agriculture extension programs). Size of communities, crop production patterns, agro-ecological characteristics, as well as other social services (access to schooling and drinking water) were similar in the respective districts. Henceforth, the communities are referred as pulse or cereal growing communities. We have also described these communities in a study on infant and young child feeding practices (Ersino, Henry, \& Zello, 2016).

The study participants in both pulse and cereal communities were mothers and their $<5 y$ old children. Using a formula for a cross-sectional study design 


$$
n_{o}=\left[Z_{1-\frac{\alpha}{2}}^{2} p(1-p)\right] / d^{2} \text { And } n=n_{o} N /\left[n_{o}+(N-1)\right]
$$

[where $n_{o}, n$ stand for sample sizes before and after applying "finite population correction" factor, respectively; $\mathrm{Z}=1.96$, $\mathrm{p}=$ probability of expected prevalence, $\mathrm{N}=$ total population of interest and $\mathrm{d}=$ margin of error] (Charan \& Biswas, 2013), a total sample size was determined as $\mathrm{N}=413$ and $\mathrm{N}=217$ mother-child pairs for the two pulseand one cereal-growing communities, respectively. Then, by applying simple random sampling, the desired mother-child pairs were selected from a list of all eligible households obtained from the local health-posts in each community.

\subsection{Data Collection Tools and Data Collectors}

A structured questionnaire (with some open-ended items) was used to collect, background characteristics, information on pulse production and consumption, diet diversity and consumption frequency of selected foods. Separate forms were used to obtain single-day weighed food records (in subsamples of $n=137$ pulse and $n=72$ cereal mother-child pairs) and anthropometric measurements from mothers and children. Survey items for assessing background characteristics (such as household size, occupation, school attendance, size of farm land, types of sanitation facility, antenatal clinic visits by mothers during most recent pregnancy and person mostly responsible for and distance/time travelled to fetch water for the household) were adapted from previous studies in similar rural settings (Tessema, Belachew, \& Ersino, 2013; Ersino, Henry, \& Zello, 2016; Ethiopian Health and Nutrition Research Institute [EHNRI], 2010; Ersino et al., 2013). Distance travelled to fetch water (half an hour or longer per round trip) was used as a proxy for presence or absence of work-burden on women.

The dietary diversity questionnaire was adapted from the Food and Agriculture Organization (FAO) guideline for measuring individual and household dietary diversity (Kennedy, Ballard, \& Dop, 2011). Mothers or caregivers were asked to recall and describe all foods and drinks (meals or snacks) consumed at home or elsewhere on the day and night before the interview day. When finished, mothers were probed to remember any food consumed in that period but not mentioned. Likewise, mothers were asked any food and drinks their child consumed over the same recall period as that of the mother. Data collectors first recorded all consumed foods and drinks on separate table that has columns for the mother and the child. Then, data collectors, with the supervision of GE, completed another table that contained 16 food groups (from the FAO guide) for the mother and child separately. A score of " 1 " or " 0 " was given depending on whether participants ate from specific food groups.

Another tool used was a food frequency questionnaire, designed to gather information on consumption frequency of common pulses, flesh foods, poultry, fish, any fruits and vegetables. Such data provided valuable information, such as, how often pulse or animal source foods were available for consumption to mothers and children, and the role of pulses in general.

All questionnaire based data were collected by trained female data collectors with some post-secondary education, mostly nurses by training.

Weighed food records were collected by the female data collectors from a subsample of mothers and 6-59months old children only. Each data collector was provided with a digital scale (2kg maximum weight: Model CS 2000; Ohaus Corporation, Parsippany, NJ, USA) and a form to record type of food consumed, with detailed description and actual amount consumed. On a separate day, the data collectors arrived at the homes of selected participants early morning (before breakfast meal) and remained until evening with the mother and child by recoding every food and drink consumed for that day. The field level data collection was supervised by GE, along with a B.Sc. nutrition graduate research assistant.

All anthropometric measurements were done by GE along with research assistants. Weight, length/height and mid-upper-arm-circumference (MUAC) were measured via electronic scale (Seca 770; Seca Corporation, Hanover, Maryland), adult/infant length/stature measuring board (Perspective Enterprises, Portage, Michigan) and insertion tape, respectively.

\subsection{Data Analysis}

\subsubsection{Weighed Food Records}

The first step in converting foods consumed to energy and nutrients was to list in Excel spreadsheet each food item consumed by participants along with amount (in grams) by using the completed weighed food record forms for each participant. A separate table was created for each subject, labeled with the subject's code. Then, a local food composition table was constructed on the spreadsheet. The local food composition table included a list of foods and drinks participants consumed along with energy and nutrient values per 100g of each food item. 
Energy and nutrient values for most of the consumed foods were obtained from Ethiopian Food Composition Tables (EFCT) (EHNRI, 1998a, 1998b). Nutrient values of some foods which were not on the EFCT were obtained by analysing samples of those foods in the laboratory following American Association of Cereal Chemists (AACC) International Methods as described in detailed in our previous publication (Ersino et al., 2016).

Once the local food composition table was completed, the per 100g in the food composition table were used to calculate energy, protein, iron, zinc and calcium values per actual amount of each food/drink consumed for each mother and child separately. Next, the totals (of energy, protein, iron, zinc \& calcium from a single-day-weighed food records) were calculated by summation. Finally, the totals of energy and selected nutrients were transferred to an SPSS spreadsheet to calculate average energy and nutrient intakes of the group. Then, median energy and nutrient intakes were compared between pulse and cereal group of mothers and children. Median energy and nutrient values of the mothers were also expressed as percent of weight-adjusted (Note 1) Estimated Energy Requirement (EER) (FAO, 2004) and Recommended Nutrient Intakes (RNI) (FAO \& World Health Organization [WHO], 2004). Protein RNI values for the mothers were taken from WHO/FAO/United Nations University [UNU] and adjusted by median weight of the mothers (WHO, FAO, \& UNU, 2007). Median intakes for children were not expressed as percentage of EER or RNI due to the existence of multiple RNIs based on age classes. Since the main emphasis here was to compare average dietary intakes of children between pulse versus cereal groups, values were not disaggregated across age classes to avoid ending up with too few observations to make meaningful comparisons between groups.

\subsubsection{Dietary Diversity}

The dietary diversity information was analysed by reducing the 16 food groups into nine main food groups, as outlined in the FAO guideline (Kennedy et al., 2011). Then, the proportion of mothers or children who ate from specific food groups was reported. The overall diet diversity scores were also calculated for both children and mothers in pulse or cereal communities and reported as medians with $1^{\text {st }}$ and $3^{\text {rd }}$ quartile values.

\subsubsection{Food Frequency}

This questionnaire was designed to obtain information on how often pulse-based foods, along with fruits and vegetables, and animal source foods were consumed over a period of a month. Frequency of consumption scores ranged from 1-4, lower scores referring to least frequent consumption and higher score more frequent consumption (i.e., a score of $1=$ food group consumed twice or less per month or never, $2=$ once or twice per week, 3=3-6 times per week, and 4= food consumed $\geq$ once per day). For each participant, a consumption index was generated by adding the scores of all food items listed in one food group and dividing it by the total number of food items listed in that food group. For example, consumption scores of $\sim$ five different types of pulses were reduced to pulse consumption index. In this way, consumption indexes were calculated for pulses, animal source foods and fruits and vegetables. Then median $\left(1^{\text {st }}, 3^{\text {rd }}\right.$ quartiles $)$ of the consumption indices were reported for either community.

\subsubsection{Anthropometry}

Anthropometric status were presented using WHO body mass index (BMI) classification criteria as undernourished/low (i.e., BMI <18.5), normal (BMI 18.5-24.9) or overweight (BMI $\geq 25$ ), as well as low MUAC for the mothers. Children's anthropometric indices (height-for-age z-score, HAZ; weight-for-height z-score, WHZ; weight-for-age z-sore, WAZ; mid-upper-arm-circumference, MUAC-for-age z-score) were calculated using WHO Anthro software (version 3.2.2) 2011. Then, prevalence of stunting (HAZ<-2 standard deviation, $\mathrm{SD}$ ), wasting (WHZ<-2SD) and underweight (WAZ<-2SD) and MUAC-for-age <-2SD were calculated. Selected background and nutrition related characteristics were used in a multiple variable model (multiple classification analysis) to predict undernutrition in mothers (using MUAC values) and children (using HAZ values) in the pooled data from both locations while including the community variable in the model.

\subsubsection{Statistics}

Background characteristics were described using descriptive statistics. Proportions were compared between pulse or cereal groups using Pearson Chi-square tests, whereas median energy and nutrient intakes as well as median consumption indices and diet diversity scores were compared using the Mann Whitney $U$ test across the pulse and cereal groups, for the mothers and children separately. Multiple Classification Analysis (MCA) (Nagpaul, 1999) was used to explore independent predictors of maternal-child nutritional status indicators. A $p<0.05$ was considered as a statistical significance. 


\section{Results}

\subsection{Background Characteristics}

The mean age of mothers interviewed in both settings was $28( \pm 6)$ years. Average household size of participants was $6( \pm 2)$ persons in either community. More than $90 \%$ of households were male-headed in each community. Cultivable land holdings were generally small as three-quarter of households from pulse and two-third of households from the cereal communities owned only $\leq 1$ hectares. Over $90 \%$ of the mothers in either study site said farming was the main occupation for their husbands while the mothers themselves were mainly housewives, not involved in income generating activities. Literacy rates among the participating mothers were low with over $80 \%$ in pulse and $70 \%$ in cereal communities reporting no formal schooling while the remaining had some primary-level schooling. Women were mostly responsible for fetching water (over $70 \%$ of the times) and the median length of time they travelled per round trip was 30 minutes in the cereal community and 60 minutes in the pulse communities.

\subsection{Background Characteristics Surrounding Pulse Production}

Table 1 presents a summary of findings based on pulse agriculture and related information to subsequent consumption by mothers and their children in participating households. Responses based on some open-ended items were included in the text to complement quantitative findings in the table. Accordingly, almost all households from the pulse growing community identified themselves as pulse growers compared with less than half in the cereal growing community $(p<0.001)$. The kidney bean was the most dominant pulse grown in the pulse community (> 93\%), whereas kidney beans and haricot beans were the pulses mainly grown by those households from the cereal group that reported growing some pulses. Production was mainly for cash income and home consumption, especially in the pulse communities. The median value for the amount of pulses produced by households, in the most recent harvest prior to the interview, was 275 and 250 kilograms for the pulse and cereal growing communities, respectively, and was not significantly different. However, pulse households in the $1^{\text {st }}$ quartile produced twice as much as cereal households in the same quartile.

Men were in charge of pulse production, particularly in the pulse growing communities, as only $2.6 \%$ of women reported co-decision making on production along with men. Although men still dominated when taking charge of pulse production in the cereal community, a significantly higher proportion $(38 \%)$ of women reported having shared control on produce $(p<0.001)$. The majority of women in either community ( $74 \%$ in pulse and $70 \%$ in cereal) had no access to land where they could grow their own preferred crops. Those women that did have access to land reported growing crops such as maize, khat, kale, millet, sorghum and potatoes.

Consumptions of pulse-based foods by mothers-children was common in both communities but the majority (76\%) of households in the cereal community obtained (purchased) their pulses from market. A significant proportion of households (39\%) in the pulse communities also purchased their pulses from market. Most commonly used pulses for food were kidney beans and peas in pulse and cereal communities, respectively. The haricot bean was the least consumed in either community. A follow up open-ended questions indicated that most common dishes made from pulses include: beans stew, boiled beans, shiro wot (stew made from roasted pea/fava bean flour) which, then, was served with bread/ Injera (Note 2) (made from maize, sorghum, millet) and boiled beans were served alone or with just coffee.

Considering maternal attitudes towards pulse-based foods, the majority of mothers from both communities expressed positive attitudes toward pulses/pulse-based foods (i.e., they 'liked it'). However, the proportion of mothers that expressed positive attitudes was significantly more in the cereal than the pulse growing community $(p<0.001)$; in addition, significantly more mothers from the cereal community said they knew some nutritional benefits of pulses than did the mothers from the pulse community $(p<0.01)$. Intentions to increase consumption or production of pulses in the future were fairly high but did not differ between groups. Some of the most frequently mentioned nutritional benefits (and reasons for intending to increase consumption of pulses) include the following: "pulses provide energy and strength for the body," "protect from anaemia," "good for overall health," "good for blood," "used as sauce/complement other foods," and "good for my child". 
Table 1. Background characteristics of study participants from Halaba or Zeway surrounding pulse crops, Ethiopia

\begin{tabular}{lll}
\hline & Pulse $_{\text {rrowing }}{ }^{a}$ & Cereal-based $^{a}$ \\
\hline Grow any pulse & $\mathrm{N}=413$ & $\mathrm{~N}=217$ \\
Yes & $389(94.2)^{* * * *}$ & $100(46.1)$ \\
Purpose of production & $\mathrm{N}=389$ & $\mathrm{n}=93$ \\
$\quad$ For cash income \& home consumption & $285(73.4)^{* * *}$ & $51(54.8)$ \\
Cash income only & $24(6.3)$ & $22(23.7)$ \\
Home consumption only & $80(20.3)$ & $20(21.5)$ \\
Size of most recent pulse harvest (kg) & $\mathrm{N}=376$ & $\mathrm{n}=88$ \\
Median $\left(25^{\text {th }} \%, 5^{\text {th }} \%\right)$ & $275(200,400)$ & $250(100,400)$ \\
Pearson in charge of production & $\mathrm{N}=386$ & $\mathrm{n}=101$ \\
Men & $376(97.4)$ & $63(62.4)$ \\
Men \& women & $10(2.6)^{* * *}$ & $38(37.6)$ \\
Mothers with access to own cultivable-land & $\mathrm{N}=408$ & $\mathrm{~N}=211$ \\
Yes & $105(25.7)$ & $63(29.9)$ \\
Consumption of pulses by mothers and children & $\mathrm{N}=413$ & $\mathrm{~N}=207$ \\
Yes & $372(90.1)$ & $180(87)$ \\
Source of pulse for consumption & $\mathrm{N}=409$ & $\mathrm{~N}=196$ \\
Own production \& purchase & $165(40.4)$ & $30(15.3)$ \\
Purchase & $160(39.1)$ & $143(75.6)$ \\
Own production & $84(20.5)$ & $14(7.1)$ \\
Food aid & $0(0)$ & $4(2)$ \\
Common pulses used for food & $\mathrm{N}=386$ & $\mathrm{~N}=177$ \\
Kidney beans & $371(95.9)$ & $64(35.8)$ \\
Pea & $179(46.3)$ & $145(81.9)$ \\
Fava bean & $79(20.5)$ & $67(37.9)$ \\
Lentil & $122(31.5)$ & $118(66.7)$ \\
Chickpea & $53(13.7)$ & $37(20.9)$ \\
Haricot bean & $26(6.7)$ & $13(7.3)$ \\
Mothers' attitude to pulse foods & $\mathrm{N}=412$ & $\mathrm{~N}=199$ \\
Like & $318(77.2)^{* * * *}$ & $185(93)$ \\
Dislike/not sure & $94(22.8)$ & $14(7)$ \\
Knowledge on pulse nutritional benefits (mothers) & $\mathrm{N}=412$ & $\mathrm{~N}=207$ \\
Yes & $168(40.8)^{* * *}$ & $113(54.6)$ \\
Intend to increase pulse consumption in future & $\mathrm{N}=413$ & $\mathrm{~N}=207$ \\
Yes & $283(68.5)$ & $154(74.4)$ \\
Intention to increase pulse production & $\mathrm{N}=390$ & $\mathrm{~N}=208$ \\
Yes & $232(59.5)$ & $110(52.9)$ \\
\hline
\end{tabular}

**, **** significant between groups at $p<0.01$ and $p<0.001$, respectively (Pearson's chi-square test); ${ }^{a}$ Values in the table represent frequency and percentage, except the item "size of pulse produce"

\subsection{Intakes of Energy and Selected Nutrients}

Energy and selected nutrient intakes by mothers and their children 6-59 months of age are summarized in Table 2. Median intakes of energy, protein, iron, zinc, and calcium were all significantly higher for mothers from the pulse communities compared with those from the cereal growing community $(p<0.001)$. In contrast, median intakes of energy, protein and zinc were significantly lower for the children from the pulse growing area $(p<0.05)$. There were no significant differences in intakes of iron and calcium between pulse and cereal children. However, compared with Recommended Nutrient Intakes (RNI), median energy intake by pulse mothers was only 58\% of the RNI, assuming average weight of the mothers and a median score for vigorous or a vigorously active lifestyle (taking into account the daily hardships of rural mothers in Ethiopia). Percent RNIs for other nutrients for pulse mothers was above requirements, except for calcium, which was $90 \%$ of the RNI. Median energy and nutrient intakes of the cereal mothers were all below requirements, except for protein. 
Table 2. Dietary intakes of energy and selected nutrients from one-day weighed food record data: median $\left(1^{\text {st }}, 3^{\text {rd }}\right.$ quartile)

\begin{tabular}{cllll}
\hline & \multicolumn{2}{c}{ Mothers } & \multicolumn{2}{c}{ Children (6-59mo) } \\
\cline { 2 - 5 } & \multicolumn{1}{c}{$\begin{array}{c}\text { Pulse growing } \\
(\mathrm{n}=137)\end{array}$} & $\begin{array}{c}\text { Cereal growing } \\
(\mathrm{n}=72)\end{array}$ & $\begin{array}{c}\text { Pulse growing } \\
(\mathrm{n}=137)\end{array}$ & $\begin{array}{c}\text { Cereal growing } \\
(\mathrm{n}=72)\end{array}$ \\
\hline${\text { Energy }(\mathrm{kcal})^{\mathrm{a}}}^{*}$ & $1574(1270,1970)^{* *}$ & $1157(864,1499)$ & $408(221,585)^{* *}$ & $549(358,779)$ \\
RNI/EER & 2700 & 2700 & - & - \\
$\%$ RNI & $58 \%$ & $43 \%$ & - & - \\
Protein (g) & $58(43,65)^{* *}$ & $42(32,55)$ & $15(8,23)^{*}$ & $18(11,31)$ \\
RNI & 42 & 42 & $10-17$ & $10-17$ \\
$\%$ RNI & $138 \%$ & $100 \%$ & - & - \\
Iron (mg) & $62(44,78)^{* *}$ & $44(29,62)$ & $15(8,26)$ & $17(8,28)$ \\
RNI & 58.8 & 58.8 & $18.6-12.6$ & $18.6-12.6$ \\
$\%$ RNI & $105 \%$ & $75 \%$ & - & - \\
Zinc (mg) & $13(10,16)^{* *}$ & $9(7,13)$ & $3(2,5) * *$ & $4(3,7)$ \\
RNI & 9.8 & 9.8 & $8.4-9.6$ & $8.4-9.6$ \\
$\%$ RNI & $133 \%$ & $92 \%$ & - & - \\
Calcium(mg) & $903(592,1203) * *$ & $448(295,651)$ & $214(112,365)$ & $213(78,466)$ \\
RNI & 1000 & 1000 & $400-600$ & $400-600$ \\
$\%$ RNI & $90 \%$ & $45 \%$ & - & - \\
\hline
\end{tabular}

${ }^{a}$ The daily recommendation of $2700 \mathrm{kcal}$ was taken from FAO/WHO/UNU joint expert consultation report for human energy requirement (FAO/WHO/UNU, 2004) and adjusted for size of the women using average weight $(50 \mathrm{~kg})$ of the mothers in the study and also assumes a physical activity level of 2.2 (the median for vigorous or vigorously active lifestyle) for non-pregnant and non-lactating women; "significant at $p<0.05$ and ${ }^{* *}$ significant at $p<0.01$ (Mann-Whitney U test, between communities); EER, estimated energy requirements; RNI, recommended nutrient intake: assumes 5\% bioavailability for iron \& low bioavailability for zinc, based on WHO/FAO recommendations (WHO/FAO, 2004). RNI values for protein are based on WHO/FAO/UNU recommendations (WHO/FAO/UNU, 2007) and were adjusted for the size of the mothers by their average weight;

\subsection{Diet Diversity}

Data on a single $24 \mathrm{~h}$ dietary diversity recall showed that most mothers and children in both communities consumed 'starchy staples' with minimal consumption from animal source foods (Table 3). Almost exclusively, the item consumed in the "dark leafy vegetable" group was Ethiopian Kale for both mothers and children in either community. The percentages of mothers and children who consumed foods from "legumes and nuts" were slightly higher in the pulse than the cereal group but not significantly different. In contrast, the proportion of mothers $(p<0.001)$ and children $(p<0.01)$ who consumed 'milk and milk products' was higher in the cereal than pulse communities. Consumption from other food groups was minimal or non-existent in both groups.

Table 3. Food groups consumed (\%) and diet diversity scores (DDS) for mothers and children $\geq 6$ mos.) in the day and night preceding the interview day

\begin{tabular}{lllll}
\hline \multirow{2}{*}{ Food groups } & \multicolumn{2}{c}{ Mothers } & \multicolumn{2}{c}{ Children } \\
\cline { 2 - 5 } & Pulse & Cereal & Pulse & Cereal \\
& $\mathrm{N}=413$ & $\mathrm{~N}=199$ & $\mathrm{n}=316$ & $\mathrm{n}=199$ \\
\hline Starchy staples & $413(100)$ & $216(100)$ & $288(86.7)$ & $190(94)^{*}$ \\
Other fruits and vegetables $^{1}$ & $404(97.8)^{* *}$ & $199(92.1)$ & $283(70.9)$ & $153(75.9)$ \\
Dark green leafy vegetables $^{2}$ & $377(91.3)$ & $169(78.2)$ & $186(56)$ & $114(56.3)$ \\
Legumes, nuts and seeds $^{3}$ & $178(43.1)$ & $83(38.4)$ & $100(29.8)$ & $56(26.6)$ \\
Milk and milk products & $49(11.9)$ & $54(25)^{* * *}$ & $79(21)$ & $79(39.2)^{* *}$ \\
Meat and fish & $3(0.7)$ & $10(4.6)^{*}$ & $2(0.6)$ & $8(4)^{*}$ \\
Eggs & $7(1.7)$ & $1(0.5)$ & $16(4.7)$ & $9(4)$ \\
Organ meat & $0(0)$ & $0(0)$ & $0(0)$ & $0(0)$ \\
Other vitamin A rich fruits and vegetables & $3(0.7)$ & $1(0.5)$ & $5(1.6)$ & $0(0)$ \\
Median $\left(1^{\text {st }}, 3^{\text {rd }}\right.$ quartile) DDS & $3(3,4)$ & $3(3,4)$ & $3(2,4)$ & $3(2,4)$ \\
\hline
\end{tabular}

${ }^{1}$ Mostly onion, tomatoes, green pepper which were added as spices/condiments than main food ingredients; ${ }^{2}$ The reported food consumed in this food group was Ethiopian kale (almost $100 \%$ of the time); ${ }^{3}$ Mostly kidney 
beans, haricot beans, lentils, pea flour ('Shiro Wot') were reported; ${ }^{*}, * * * * *$ significant at $p<0.05, p<0.01$ and $p<0.00$ respectively, between groups (Pearson's chi-square test);

Based on the nine FAO food groups, the median dietary diversity scores (DDS) for both mothers and children of either community was only three. Only three (3) food groups (i.e., 'starchy staples', 'other fruits and vegetables' and 'green leafy vegetable') were consumed by $\geq 50 \%$ of the mothers and their young children in either community.

\subsection{Consumption of Common Pulses and other Foods Based on Food Frequency Questionnaire}

Responses from mothers on their own and their children's consumption frequency of common pulses and other food groups are summarised as consumption indexes in Table 4. An index closer to 1 means consumption from a food -group was only 'twice or less or never' per month, whereas an index closer to ' 4 ' indicates a consumption frequency of 'once or more than once' per day. Accordingly, the median consumption index of both 'pulses' and 'fruits and vegetables' was significantly higher for mothers and children in pulse than cereal group $(p<0.001)$. However, consumption indexes for 'animal source foods' were significantly higher in cereal than pulse mothers and children $(p<0.001)$.

Table 4. Consumption indexes, based on food frequency questionnaire of pulse and other food groups: median $\left(1^{\text {st }}, 3^{\text {rd }}\right.$ quartiles $)$

\begin{tabular}{cll}
\hline & Pulse growing & Cereal growing \\
\hline Consumption index for mothers & $\mathrm{N}=413$ & $\mathrm{~N}=204$ \\
Any animal product (meat/fish/poultry/dairy) & $1.25(1,1.75) * * *$ & $1.5(1.25,1.75)$ \\
& $\mathrm{N}=411$ & $\mathrm{~N}=214$ \\
& $2.5(2.0,3.0) * * *$ & $2.5(1.5,2.5)$ \\
Any fruits or vegetable & $\mathrm{N}=413$ & $\mathrm{~N}=205$ \\
& $2(1.75,2.5) * * *$ & $1.5(1.25,2)$ \\
Pulse (lentil/peas/kidney bean/broad bean) & $\mathrm{n}=289$ & $\mathrm{n}=177$ \\
Consumption index for children (6-59months) & $1.25(1,1.75) * * *$ & $1.5(1.25,1.75)$ \\
Any animal product (meat/fish/poultry/dairy) & $\mathrm{n}=282$ & $\mathrm{n}=187$ \\
& $2.5(2.0,3.0) * * *$ & $2.5(1.5,2.5)$ \\
Any fruits or vegetable & $\mathrm{n}=287$ & $\mathrm{n}=179$ \\
& $2(1.5,2.5) * * *$ & $1.5(1.25,2)$ \\
\hline
\end{tabular}

Note: Scores ranged from 1-4 (a score of $1=$ food group consumed twice or less per month or never, $2=$ once or twice per week, $3=3-6$ times per week, and $4=$ food consumed $\geq$ once per day); ${ }^{* * *}$ Significant at $p<0.001$, Mann-Whitney $U$ (2-tailed)

\subsection{Anthropometry}

Prevalence of undernutrition in mothers was as high as $22 \%$ in pulse community, whereas it was $14 \%$ among those from the cereal community (Table 5). The majority of the mothers had a normal BMI range and prevalence of overweight or obesity was very minimal. There were no statistical differences between groups.

Findings on child anthropometry also indicated that prevalence of child stunting and wasting (indicators of chronic and acute levels of child undernutrition) were 54\% and $10 \%$ in the pulse and $42 \%$ and $4 \%$ in the cereal group, respectively. Differences were significant between groups $(p<0.05)$. Likewise, levels of underweight, a combination of stunting and wasting, were $37 \%$ in pulse children and $22 \%$ in the cereal; the difference was significant $(p<0.001)$. 
Table 5. Anthropometric status of mothers and children in pulse or cereal communities,

\begin{tabular}{lll}
\hline & Pulse growing & Cereal growing \\
\hline $\begin{array}{l}\text { Maternal Anthropometry } \\
{ }^{\mathrm{a}} \text { Body mass index }\left(\mathrm{kg} / \mathrm{m}^{2}\right) \text { categories (\%) }\end{array}$ & $\mathrm{n}=266$ & $\mathrm{n}=142$ \\
$\quad$ & $58(21.8)$ & $20(14.1)$ \\
$\quad$ Underweight (BMI <18.5) & $201(75.6)$ & $110(77.5)$ \\
$\quad$ Normal range (BMI 18.5-24.99) & $7(2.6)$ & $12(8.4)$ \\
Overweight or Obese (BMI 25.00-29.99) & $\mathrm{N}=341$ & $\mathrm{~N}=163$ \\
& $92(27)$ & $38(23)$ \\
MUAC <23 cm (undernourished) $\%$ & $\mathrm{~N}=355$ & $\mathrm{~N}=170$ \\
Child Anthropometry & & \\
Prevalence estimates (\%) & $190(53.5)^{*}$ & $71(41.8)$ \\
Stunting (HAZ <-2SD) & $37(10.4)^{*}$ & $7(4.1)$ \\
Wasting (WHZ <-2SD) & $130(36.5)^{* * * *}$ & $37(21.6)$ \\
Underweight (WAZ <-2SD) & $\mathrm{n}=315$ & $\mathrm{n}=169$ \\
& $95(30.2)$ & $42(24.9)$ \\
\hline${ }^{\mathrm{b}}$ MUAC-for-age <-2SD & &
\end{tabular}

${ }^{a}$ Excludes pregnant or pregnant and lactating mothers as well as those who had babies within the last two months prior to the anthropometric measurement; MUAC, mid-upper arm circumference; HAZ, height-for-age Z-score; WHZ, weight-for-height Z-score; WAZ, weight-for-age Z-score; ${ }^{\mathrm{b}}$ Minimum child age for the anthropometric indices in these groups is 3 months; ${ }^{* * * *}$ significant between groups at $p<0.05$ and $p<0.001$ (Pearson's chi-square test)

\subsection{Multivariate Analysis on Predictors of Child Stunting and Maternal Undernutrition}

In multiple regression analysis, the effects of selected household and individual level factors on child and maternal anthropometry (height-for-age z-score and mid-upper-arm-circumference, respectively) are shown in Tables 6 and 7 based on pooled data that included both pulse and cereal communities. In Table 6 , the regression model for HAZ of children was very significant, predicting up to $25 \%$ of the variation in the outcome variable $\left(\mathrm{R}^{2}: 0.248\right), p<0.001$. After adjustment for all other factors in the model, child age $(p<0.001)$, being from the pulse or cereal community $(p<0.001)$, household size $(p<0.001)$, amount of land owned by the household $(p<0.05)$ and maternal age $(p<0.05)$, in order of importance, were significant predictors of HAZ of children in both communities.

After adjustment for other factors included in the model, the mean HAZ score significantly dropped (became worse) for older children ( $\geq 24$ months), whereas children in households of larger family size ( $\geq 6$ members) appeared to have better HAZ scores compared to those in households with $<6$ membership. The HAZ scores for the children $\geq 24$ months were much lower than the grand mean (overall average) of all factors. Being from the pulse rather than cereal-based community meant significantly lower HAZ score. Likewise, the HAZ score of children from households with smaller cultivable land size tended to be lower, whereas that of children of younger women appeared to be higher compared with those of older women.

Other factors in the model did not show significant influence on HAZ scores though they showed some trends. For example, children whose mothers had four or more ANC visits during the most recent pregnancy and children who lived in households with access to improved sanitation facility generally had better HAZ scores.

Table 7 provides similar information on predictors of maternal malnutrition as measured by mid-upper arm circumference (MUAC). Variables in the adjusted model that significantly predicted variation in maternal MUAC based on pooled data from both communities were number of ANC visits, amount of land owned by households, household size, frequency of consumption of dairy products by mothers, work-burden on mothers, child stunting status and access to own land by mothers, in order of importance. The overall model significantly explained about $10.2 \%$ of the variation in the dependent variable $\left(\mathrm{R}^{2}=0.102, p<0.001\right)$.

For those variables that significantly predicted variation in maternal MUAC, the direction of association was as expected, except for household size. For example, the mean MUAC of mothers were significantly higher for those mothers who had ANC visits more frequently or in households with larger amount of cultivable land, or for mothers who reported more frequent consumption of dairy products, or those who had no work-burden. Other variables included in the model, such as pulse consumption, frequency of poultry product consumption, or being from pulse or cereal growing community, did not have significant effects on maternal MUAC in the pooled data. 
Table 6. Predictors of child height-for-age-z-scores (HAZ), using Multiple Classification Analysis, in pulse or cereal growing rural communities, Ethiopia

\begin{tabular}{|c|c|c|c|c|c|}
\hline \multirow[t]{2}{*}{ Variables } & \multicolumn{5}{|c|}{ Mean HAZ } \\
\hline & $\mathrm{n}$ & Unadjusted & $\operatorname{Eta}(\eta)$ & Adjusted for Factor & $\operatorname{Beta}(\beta)$ \\
\hline \multicolumn{6}{|l|}{ Household size } \\
\hline$<6$ & 209 & -2.19 & \multirow[t]{2}{*}{.147} & -2.19 & \multirow[t]{2}{*}{$.147^{* * *}$} \\
\hline 6 or more & 284 & -1.72 & & -1.72 & \\
\hline \multicolumn{6}{|c|}{ Husband's educational status } \\
\hline No formal education & 223 & -1.99 & \multirow[t]{3}{*}{.040} & -1.82 & \multirow[t]{3}{*}{.056} \\
\hline Primary level & 178 & -1.87 & & -2.00 & \\
\hline Post-primary level & 92 & -1.84 & & -2.00 & \\
\hline \multicolumn{6}{|l|}{ Child sex } \\
\hline Female & 254 & -1.82 & \multirow[t]{2}{*}{.064} & -1.83 & \multirow[t]{2}{*}{.055} \\
\hline Male & 239 & -2.03 & & -2.01 & \\
\hline \multicolumn{6}{|c|}{ Household cultivated land size } \\
\hline 0.5 or less hectare & 158 & -2.09 & \multirow[t]{3}{*}{.145} & -2.14 & \multirow[t]{3}{*}{$.111^{*}$} \\
\hline $0.6-1$ hectare & 202 & -2.04 & & -1.91 & \\
\hline$>1$ hectare & 133 & -1.54 & & -1.68 & \\
\hline \multicolumn{6}{|l|}{ Maternal age (in years) } \\
\hline $15-24$ & 104 & -1.85 & \multirow[t]{3}{*}{.026} & -1.69 & \multirow[t]{3}{*}{$.075^{*}$} \\
\hline $25-34$ & 312 & -1.93 & & -1.98 & \\
\hline $35-49$ & 77 & -1.98 & & -2.00 & \\
\hline \multicolumn{6}{|l|}{ Number of ANC visits } \\
\hline$<4$ visits & 333 & -2.00 & \multirow[t]{2}{*}{.069} & -2.00 & \multirow[t]{2}{*}{.074} \\
\hline$\geq 4$ visits & 160 & -1.76 & & -1.75 & \\
\hline \multicolumn{6}{|l|}{ Age of child (in months) } \\
\hline$<6$ & 82 & -.85 & \multirow[t]{3}{*}{.362} & -.63 & \multirow[t]{3}{*}{$.449^{* * *}$} \\
\hline $6-23.99$ & 234 & -1.81 & & -1.76 & \\
\hline$\geq 24$ & 177 & -2.55 & & -2.72 & \\
\hline \multicolumn{6}{|l|}{ Work burden on mothers ${ }^{a}$} \\
\hline No & 134 & -1.89 & \multirow[t]{2}{*}{.011} & -2.04 & \multirow[t]{2}{*}{.044} \\
\hline Yes & 359 & -1.93 & & -1.88 & \\
\hline \multicolumn{6}{|c|}{ Household sanitation facility } \\
\hline Unimproved & 221 & -1.95 & \multirow[t]{2}{*}{.017} & -1.96 & .024 \\
\hline Improved & 272 & -1.89 & & -1.89 & \\
\hline Community & & & & & \\
\hline Pulse producer & 338 & -2.09 & .152 & -2.22 & $.274^{* * *}$ \\
\hline Cereal-based & 155 & -1.56 & & -1.27 & \\
\hline
\end{tabular}

$\mathrm{R}=0 . \overline{498 ;} \mathrm{R}^{2}=0.248$; Grand mean $=-1.92$; Number of cases $=493 ;{ }^{*}$ significant at $p<0.05 ;{ }^{* * *}$ significant at $p<0.001$; Model: $F(14)=2.163, p<0.001$

Abbreviations: ANC, Antenatal clinic; $\eta=$ coefficient for the bivariate association; $\beta=$ coefficient for the multivariate association; ${ }^{a}$ work burden was measured using distance travelled to fetch water (half hour or longer per trip) as a proxy. 
Table 7. Predictors of maternal mid-upper-arm-circumference (MUAC), using Multiple Classification Analysis, in pulse or cereal growing rural communities, Ethiopia

\begin{tabular}{|c|c|c|c|c|c|}
\hline \multirow[b]{2}{*}{ Variables } & \multicolumn{5}{|c|}{ Mean MUAC (in centimeters) } \\
\hline & $\mathrm{n}$ & Unadjusted & Eta $(\eta)$ & $\begin{array}{l}\text { Adjusted for } \\
\text { Factor }\end{array}$ & Beta $(\beta)$ \\
\hline \multicolumn{6}{|l|}{ Household size } \\
\hline$<6$ & 188 & 24.3 & .143 & 24.4 & $.097^{* *}$ \\
\hline 6 or more & 262 & 25.1 & & 25.0 & \\
\hline \multicolumn{6}{|l|}{ Pulse consumption index for mothers } \\
\hline$\leq 2$ (Less frequent consumption) & 288 & 24.7 & .000 & 24.7 & .000 \\
\hline$>2$ (More frequent consumption) & 162 & 24.7 & & 24.7 & \\
\hline \multicolumn{6}{|l|}{ Child's stunting status } \\
\hline Not stunted & 224 & 25.0 & .102 & 24.9 & $.066^{*}$ \\
\hline Stunted & 226 & 24.5 & & 24.6 & \\
\hline \multicolumn{6}{|l|}{ Household cultivated land size } \\
\hline 0.5 or less hectare & 147 & 24.2 & .174 & 24.3 & $.108^{* *}$ \\
\hline 0.6 - 1 hectare & 183 & 24.7 & & 24.8 & \\
\hline$>1$ hectare & 120 & 25.5 & & 25.1 & \\
\hline \multicolumn{6}{|l|}{ Mothers access to land (own) } \\
\hline No & 333 & 24.6 & .103 & 24.6 & $.061^{*}$ \\
\hline Yes & 117 & 25.2 & & 25.0 & \\
\hline \multicolumn{6}{|l|}{ Number of ANC visits } \\
\hline$<4$ visits & 305 & 24.4 & .185 & 24.4 & $.166^{* * *}$ \\
\hline$\geq 4$ visits & 145 & 25.5 & & 25.4 & \\
\hline \multicolumn{6}{|l|}{ Frequency of consumption of any dairy } \\
\hline Less frequent (twice or less/month) & 171 & 24.3 & .131 & 24.4 & $.101^{*}$ \\
\hline More frequent (1-2 times or more/week) & 279 & 25.0 & & 25.0 & \\
\hline \multicolumn{6}{|l|}{ Work-burden on mothers $^{\text {a }}$} \\
\hline No & 120 & 25.3 & .118 & 25.1 & $.087^{*}$ \\
\hline Yes & 330 & 24.5 & & 24.6 & \\
\hline \multicolumn{6}{|l|}{ Frequency of consumption of any poultry } \\
\hline Less frequent (twice or less/month) & 334 & 24.7 & .052 & 24.7 & .018 \\
\hline More frequent (1-2 times or more/week) & 116 & 25.0 & & 24.9 & \\
\hline \multicolumn{6}{|l|}{ Community } \\
\hline Pulse producer & 319 & 24.6 & .084 & 24.7 & .022 \\
\hline Cereal-based & 131 & 25.1 & & 24.8 & \\
\hline
\end{tabular}

ANC, Antenatal clinic; $\eta=$ coefficient for the bivariate association; $\beta=$ coefficient for the multivariate association;

a work burden was measured using distance travelled to fetch water (half hour or longer per trip) as a proxy;

\section{Discussion}

The purpose of this study was to explore evidence of pulse agriculture translating to nutritional health benefits by assessing the nutrition situation of mothers and children in pulse and cereal growing communities. We found that maternal dietary intake of energy and selected other nutrients (i.e. protein, iron, zinc and calcium) were significantly better for mothers in the pulse-growing communities than in the cereal growing community. However, energy, protein and zinc intakes of children were lower in pulse growing communities than the cereal group, while intakes of other nutrients did not differ among children between communities. The Median DDS and consumption from various food groups did not differ between communities in either mother or child groups - except consumption of "milk and milk products" and "meat and fish" were reported by a higher proportion of cereal mothers and children. Consumption indexes for 'pulse' and 'fruits-vegetables' were significantly better in both mothers and children of the pulse- than the cereal-growing communities. However, consumption indexes for 'any animal product' were significantly higher for mothers and children in the cereal community. 
Despite the study's hypothesis and the observed higher maternal energy and nutrient intakes, and better consumption indexes of "fruits and vegetables" and "pulses", high levels of maternal undernutrition (22\%) was found in the pulse community compared with a moderate level (14\%) in the cereal community. Children from pulse communities, where intakes of energy and nutrients were lower, presented higher levels of stunting, wasting and underweight - though stunting prevalence was 'very high' by WHO standard in both communities. Factors which significantly predicted HAZ in children include: child age, being in pulse or cereal community, household size, household land size and maternal age. It is worth noticing that larger household size unexpectedly showed protective effect on HAZ of children and maternal MUAC (i.e., significantly higher mean HAZ and MUAC values for those children and mothers from larger households).

Moderate to high levels of maternal undernutrition is a concern repeatedly documented both in national surveys and smaller studies in Ethiopia (CSA \& ICF International, 2012; EHNRI, 2010; C. Negash, Whiting, Henry, Belachew, \& Hailemariam, 2015; Regassa \& Stoecker, 2012). Studies that examined dietary practices or estimated energy and nutrient intakes in mothers or rural women of reproductive age have been limited. Despite the strong evidence (Black et al., 2008; Black et al., 2013; Horton, 2008; Lartey, 2008; Victora et al., 2008) that improving nutrition of mothers sets the foundation for better nutritional status of both the child and mother, research somehow appears to have focused much more on the feeding practices of infants and young children, with limited attention to the mothers themselves. This could be due to the strong advocacy on improving childhood nutrition, particularly of infants and young children. As a result, most studies in Ethiopia tend to focus on breastfeeding and complementary feeding of children.

In this study, we examined dietary intakes of both mothers and children using multiple dietary assessment tools. The results only partially met our hypothesis that diets and nutritional status would be better for women and children in pulse than cereal-growing communities. Despite the low consumption of animal source foods, dietary intakes were generally higher for mothers in the pulse communities. However, this was not true for the children, indicating a gap in caring practices. The existence of gaps in child caring practices is supported by our findings on suboptimum infant and child feeding practices we reported in a related study (Ersino et al., 2016). The prevalence of higher maternal undernutrition in the pulse mothers despite their relatively better nutrient and caloric intake could be due to contextual factors such as access to own land, family size, and high work-burden in pulse mothers, which also significantly predicted lower maternal MUAC in the multiple variable analysis. Though evidence on dietary intakes among non-pregnant women was limited, lower intakes energy and nutrients (such as $\mathrm{Fe} \& \mathrm{Zn}$ ) have been reported among rural pregnant women from other parts of southern Ethiopia (Abebe et al., 2008; Gibson et al., 2008).

Dietary diversity can be used as an important proxy indicator for micronutrient adequacy of both women's (FAO \& Family Health International 360, 2016) and children's diets (WHO, 2008). Studies in Ethiopia and elsewhere have shown the association between maternal and child dietary diversity (Nguyen et al., 2013), as well as its association with stunting (Rah et al., 2010). The low dietary diversity scores and heavy dependence on a few staples from only one or two food groups reported here was also concerning. At least $75 \%$ of mothers and children from either group consumed only from four or less food groups out of nine main food groups, and consumption from animal source foods was minimal or almost negligible. The median DDS for both mothers and children could have gone lower than three if food items such as tomatoes, onions and green peppers were not given a score of " 1 " since they were consumed only as spices and condiments. Such a low DDS of the women in both communities is more concerning in light of the new recommendation of $\geq 5$ food groups as minimum dietary diversity for women (FAO \& Family Health International 360, 2016). However, our finding was not unique as this scenario had been previously reported by other studies and national reports (Abebe et al., 2008; CSA \& ICF International, 2012; EHNRI, 2010; Ersino, Tadele, Bogale, Abuye, \& Stoecker, 2013; Gibson et al., 2009; Gibson et al., 2008; Tessema et al., 2013).

Of note is that the proportion of pulse mothers or children consuming 'legumes, nuts and seeds' were not that large or significantly different compared with the cereal group. Although consumption indexes of pulses were significantly higher in pulse groups, the median score of two reflected consumption of pulses only once or twice/week. Several factors might have contributed to the low consumption and overall poorer nutritional status in the pulse group. Indeed, most households (94\%) in the pulse group produced some pulse crops; however, production was almost entirely controlled by men and the proportion of households where both men and women co-control pulse production was $<3 \%$. The fact that only $20 \%$ of the pulse households used their 'own production' as their main source of pulses consumed at home despite all being pulse producers-probably indicates that much of the pulses they produced were sold at market. The lack of knowledge on nutrition benefit of pulses and significantly lower positive attitude to pulse-foods might have played a role in the poor pulse 
consumption. The low consumption of pulse based foods in this area has also been previously reported among adolescent girls (Roba et al., 2015).

As pointed out earlier, the MCA also revealed contextual factors that contributed to the poor nutrition of mother-children in pulse or cereal groups. Children of older mothers (35-49y), those children older than 24 months, children from pulse-growing communities, and from households with smaller land size had worse mean HAZ scores after controlling for all other factors in the adjusted model. This could be due to the fact that older mother, who had lower formal schooling (result not shown), may also have had lower nutrition literacy to provide appropriate care for their children; this is in agreement with reports of national surveys where lower maternal schooling is associated with higher stunting in children (CSA, 2014; CSA \& ICF International, 2012). The fact that older children were worse on their HAZ score could also show the poor dietary and sanitary environment for young children, particularly after they stopped breastfeeding. Likewise, pulse mothers with no access to land, with stunted children, $<4$ times antenatal visits, and with work-burden had significantly lower mean MUAC, indicating the importance of access to health/nutrition services and important resources such as land.

Many of the pulse-related and other factors (from regression analysis) that influenced poor consumption or nutritional status, particularly in the pulse group, could be improved through provision of basic nutrition education that highlights benefits of pulses. Such interventions may help pulse-growing communities consume pulses, and/ or utilize cash generated from pulse sales for the purchase of fruits and vegetables not grown in their communities. The education should also advocate priorities for mothers and children in intrahousehold food distribution. Empowering women to increase their access to their own piece of land-where they could potentially grow food for home consumption - and increasing their participation in decision making regarding pulse produce in the home, will have positive influence in improving the nutrition of their family and of themselves. Minimizing the work burden of women by ensuring access to drinking water in close proximity is also another area that needs the government's attention. Empowering women by improving their access to land (Allendorf, 2007), increasing their livestock co-ownership/ownership (Jin \& Iannotti, 2014) or ensuring income from employment or other sources (Negash et al., 2015) have been shown to have positive associations with improved child nutritional status. Despite the fact pulses have been an integral part of the Ethiopian diet for many years (Ethiopian Export Promotion Agency, 2004), this study was one of the first few that attempted to link pulse production and nutritional health in a comparative study involving traditionally pulse-growing and cereal-based communities. The strength of the study was the use of weighted food records (complemented by multiple other dietary assessment tools) to examine dietary intakes in mothers and children. The study has some limitations. Consumption indexes of food groups were based on recalls over longer time frame. Although this did not affect the accuracy of frequently consumed foods, rarely consumed foods such as flesh foods might not have been reported accurately. Weighed food records were taken only for one day and hence, usual intakes of individuals or prevalence of risk of inadequacy of energy and nutrients were not estimated. Given the poor consumption of fruits and vegetables, micronutrient deficiencies could exist but not covered in our analysis.

\section{Conclusions}

Overall, dietary intake, consumption patterns and nutritional status of mothers and children appeared to be poor in both pulse and cereal communities in rural Ethiopia. Lack of access to own land and work-burden on women might have aggravated poor nutritional status in the pulse community. Though pulse mothers had higher levels of energy and nutrient intake, their children had a significantly lower intake compared with their cereal counterparts. In addition, the median energy intake of the mothers was much lower than estimated energy requirements in both pulse and cereal groups. Dietary diversity scores were low in both communities and the proportions in the pulse community that consumed pulse-based foods did not exceed those in the cereal community, although almost all pulse households reported growing pulses. The median pulse-consumption-index score of the pulse community, though higher than the cereal, still indicated infrequent (once or twice/week) consumption of any pulses despite the poor consumption of animal source foods, indicating pulse production does not necessarily translate to consumption and associated nutritional benefits. Nutrition education in the pulse communities may improve consumption and potential nutritional benefits of pulses traditionally grown in the area.

\section{Acknowledgement}

The research was supported by the International Development Research Centre (IDRC) and Global Affairs Canada, Government of Canada, through the Canadian International Food Security Research Fund (CIFSRF). The funding agency had no role in the design, implementation, analysis/interpretation and writing of this manuscript. The participation of the data collectors, as well as, the mothers and their young children was greatly 
appreciated.

\section{Competing interests}

The authors declare no competing interests.

\section{Ethics approval and consent to participate}

The study was approved by the University of Saskatchewan Behavioural Ethics Board (\#12-357) and permission was received from the Health Bureaus of the respective Regions where the study was conducted. Participant mothers gave oral consent to participate in the study which was then confirmed by writing down their name in the consent form by the local research assistants.

\section{References}

Abebe, Y., Bogale, A., Hambidge, K. M., Stoecker, B. J., Arbide, I., Teshome, A., ... Gibson, R. S. (2008). Inadequate intakes of dietary zinc among pregnant women from subsistence households in Sidama, Southern Ethiopia. Public Health Nutrition, 11(4), 379-386. https://doi.org/10.1017/S1368980007000389

Allendorf, K. (2007). Do Women's Land Rights Promote Empowerment and Child Health in Nepal? World Development, 35(11), 1975-1988. https://doi.org/10.1016/j.worlddev.2006.12.005

Black, R. E., Allen, L. H., Bhutta, Z. A., Caulfield, L. E., de Onis, M., Ezzati, M., ... Child Undernutrition Study, Group. (2008). Maternal and child undernutrition: global and regional exposures and health consequences. Lancet, 371(9608), 243-260. https://doi.org/10.1016/S0140-6736(07)61690-0

Black, R. E., Victora, C. G., Walker, S. P., Bhutta, Z. A., Christian, P., de Onis, M., ... Child Nutrition Study Group. (2013). Maternal and child undernutrition and overweight in low-income and middle-income countries. Lancet, 382(9890), 427-451. https://doi.org/10.1016/S0140-6736(13)60937-X

Charan, J., \& Biswas, T. (2013). How to calculate sample size for different study designs in medical research? Indian J Psychol Med, 35(2), 121-6.

CSA. (2014). Ethiopia Mini Demographic and Health Survey 2014. Addis Ababa, Ethiopia: Central Statistical Agency.

CSA \& ICF International. (2012). Ethiopia Demographic and Health Survey 2011. Addis Ababa, Ethiopia \& Calverton, MD: Central Statistical Agency \& ICF International.

CSA and ORC Marco. (2006). Ethiopian Demographic and Health Survey 2005. Addis Ababa, Ethiopia \& Calverton, MD: Central Statistical Agency and ICF International.

EHNRI. (1998a). Food composition table for use in Ethiopia (1968-1997): Part III. Addis Ababa, Ethiopia: Ethiopian Health and Nutrition Research Institute (EHNRI).

EHNRI. (1998b). Food compostion table for use in Ethiopia (1995-1997): Part IV. Addis Ababa, Ethiopia: Ethiopian Health and Nutrition Research Institute (EHNRI)

EHNRI. (2010). Nutrition baseline survey report for the National Nutrition Program of Ethiopia. Retrieved from http://www.ephi.gov.et/images/nutrition/nutrition\%20baseline\%20survey\%20report.pdf

Ersino, G., Henry, C. J., \& Zello, G. A. (2016). Suboptimal feeding practices and high levels of undernutrition among infants and young children in the rural communities of Halaba and Zeway, Ethiopia. Food Nutrition Bulletin. https://doi.org/10.1177/0379572116658371

Ersino, G., Tadele, H., Bogale, A., Abuye, C., \& Stoecker, B. J. (2013). Clinical assessment of goiter and low urinary iodine concentration depict presence of severe iodine deficiency in pregnant Ethiopian women: a cross-sectional study in rural Sidama, southern Ethiopia. Ethiopian Medical Journal, 51(2), 133-141.

Ethiopian Export Promotion Agency. (2004). Ethiopia, Land of Crop Diversity: Ethiopian Pulses Profile. Retrieved from http://www.eap.gov.et/sites/default/files/Ethiopian\%20Pulses\%20Profile.pdf.

FAO. (2004). Human energy requirements: Report of a Joint FAO/WHO/UNU Expert Consultation Rome, 17-24 October 2001. Retrieved from http://www.fao.org/3/a-y5686e.pdf

FAO, \& Family Health International 360. (2016). Minimum dietary diversity for women: A guide for measurement. Rome, Italy: Food and Agriculture Organization of the United Nations.

FAO, \& WHO. (2004). Vitamin and mineral requirements in human nutrition (Second ed.). Geneva. Switzerland and Rome, Italy World Health Organization and Food and Agriculture Organization of the United Nations.

Gebremedhin, S., Enquselassie, F., \& Umeta, M. (2011). Prevalence of prenatal zinc deficiency and its 
association with socio-demographic, dietary andhealth care related factors in Rural Sidama, Southern Ethiopia: A cross-sectional study. BMC Public Health, 11, 898. https://doi.org/10.1186/1471-2458-11-898

Gibson, R. S., Abebe, Y., Hambidge, K. M., Arbide, I., Teshome, A., \& Stoecker, B. J. (2009). Inadequate feeding practices and impaired growth among children from subsistence farming households in Sidama,

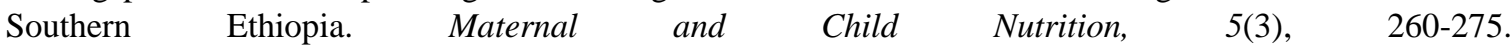
https://doi.org/10.1111/j.1740-8709.2008.00179.x

Gibson, R. S., Abebe, Y., Stabler, S., Allen, R. H., Westcott, J. E., Stoecker, B. J., ... Hambidge, K. M. (2008). Zinc, gravida, infection, and iron, but not vitamin B-12 or folate status, predict hemoglobin during pregnancy in southern Ethiopia. Journal of Nutrition, 138(3), 581-586.

Horton, R. (2008). Maternal and child undernutrition: an urgent opportunity. Lancet, 371(9608), 179. https://doi.org/10.1016/S0140-6736(07)61869-8

IFPRI. (2010). Pulses value chain potential in Ethiopia: Constrains and opportunities for enhancing exports. Retrieved from https://ethiopianagriculture.files.wordpress.com/2010/11/ethiopia-pulses-value-chain-diagnostic-july-20101.pdf

Jin, M., \& Iannotti, L. L. (2014). Livestock production, animal source food intake, and young child growth: the role of gender for ensuring nutrition impacts. Social Science and Medicine, 105, 16-21. https://doi.org/10.1016/j.socscimed.2014.01.001

Kebebu, A., Whiting, S. J., Dahl, W. J., Henry, C. J., \& Abegaz, K. (2013). Formulation of a complementary food fortified with broad beans (Vicia faba) in southern Ethiopia. African J of Food, Agriculture, Nutrition and Development, 13(3), 7789-7803.

Kennedy, G., Ballard, T., \& Dop, M. C. (2011). Guidelines for measuring household and individual dietary diversity. Rome, Italy Food and Agriculture Organization of the United Nations.

Lartey, A. (2008). Maternal and child nutrition in Sub-Saharan Africa: challenges and interventions. Proceedings of the Nutrition Society, 67(1), 105-108. https://doi.org/10.1017/S0029665108006083

Mulualem, D., Henry, C. J., Berhanu, G., \& Whiting, S. J. (2016). The effectiveness of nutrition education: Applying the Health Belief Model in child-feeding practices to use pulses for complementary feeding in Southern Ethiopia. Ecology of Food and Nutrition, 55(3), 308-323. https://doi.org/10.1080/03670244.2016.1161617

Nagpaul, P. S. (1999). Guide to advanced data analysis using IDAMS Software. Retrieved from http://www.unesco.org/webworld/idams/advguide/TOC.htm

Negash, C., Whiting, S. J., Henry, C. J., Belachew, T., \& Hailemariam, T. G. (2015). Association between maternal and child nutritional status in Hula, rural southern Ethiopia: A Cross sectional study. PloS One, 10(11), e0142301. https://doi.org/10.1371/journal.pone.0142301

Negash, C., Belachew, T., Henry, C. J., Kebebu, A., Abegaz, K., \& Whiting, S. J. (2014). Nutrition education and introduction of broad bean-based complementary food improves knowledge and dietary practices of caregivers and nutritional status of their young children in Hula, Ethiopia. Food Nutrition Bulletin, 35(4), 480-486. https://doi.org/10.1177/156482651403500409

Nguyen, P. H., Avula, R., Ruel, M. T., Saha, K. K., Ali, D., Tran, L. M., ... Rawat, R. (2013). Maternal and child dietary diversity are associated in Bangladesh, Vietnam, and Ethiopia. The Journal of Nutrition, 143(7), 1176-1183. https://doi.org/10.3945/jn.112.172247

Ofuya, Z. M., \& Akhidue, V. (2005). The role of pulses in human nutrition: A review. Journal of Applied Sciences and Environmental Managment, 9(3), 99-104.

Pulse Canada. (2012). Fact Sheets: Protein Quality of Cooked Pulses (PDCAAS Method). Retrieved from http://www.pulsecanada.com/uploads/ff/28/ff280f2f10206d5a53a241ef6e2e2d25/USA_PC_protein_fact_sh eet_p6.pdf

Pulse Canada. (2016). Food and Health: Nutritional Benefits. Retrieved from http://www.pulsecanada.com/food-health/nutritional-benefits

Rah, J. H., Akhter, N., Semba, R. D., de Pee, S., Bloem, M. W., Campbell, A. A., ... Kraemer, K. (2010). Low dietary diversity is a predictor of child stunting in rural Bangladesh. European Journal of Clinical Nutrition, 64(12), 1393-1398. https://doi.org/10.1038/ejcn.2010.171 
Regassa, N., \& Stoecker, B. J. (2012). Contextual risk factors for maternal malnutrition in a food-insecure zone in southern Ethiopia. Journal of Biosocial Science, 44(5), 537-548. https://doi.org/10.1017/S002193201200017X

Roba, A. C., Gabriel-Micheal, K., Zello, G. A., Jaffe, J., Whiting, S. J., \& Henry, C. J. (2015). A low pulse food intake may contribute to the poor nutritional status and low dietary intakes of adolescent girls in rural southern ethiopia. Ecology of Food and Nutrition, 54(3), 240-254. https://doi.org/10.1080/03670244.2014.974593

Tessema, M., Belachew, T., \& Ersino, G. (2013). Feeding patterns and stunting during early childhood in rural communities of Sidama, South Ethiopia. Pan African Medical Journal, 14, 75. https://doi.org/10.11604/pamj.2013.14.75.1630

Victora, C. G., Adair, L., Fall, C., Hallal, P. C., Martorell, R., Richter, L., ... Child Undernutrition Study Group. (2008). Maternal and child undernutrition: consequences for adult health and human capital. Lancet, 371(9609), 340-357. https://doi.org/10.1016/S0140-6736(07)61692-4

WHO. (2008). Indicators for assessing infant and young child feeding practices: Part-I Definitions, conclusions of a consensus meeting held 6-8 November 2007 in Washington, DC, USA. Retrieved from http://www.who.int/nutrition/publications/infantfeeding/9789241596664/en/index.html

WHO, FAO, \& UNU. (2007). Protein and amino acid requirements in human nutrition: Report of a Joint FAO/WHO/UNU Expert Consultation (935). Retrieved from http://www.who.int/nutrition/publications/nutrientrequirements/WHO_TRS_935/en/

\section{Notes}

Note 1. EER was adjusted for the size of the mothers by using the average weight of the mothers in the study.

Note 2. Injera is a flat bread mostly made from a cereal called 'teff' which is common only in Ethiopia. But Injera can be made from other cereals such as maize, sorghum and millets.

\section{Copyrights}

Copyright for this article is retained by the author(s), with first publication rights granted to the journal.

This is an open-access article distributed under the terms and conditions of the Creative Commons Attribution license (http://creativecommons.org/licenses/by/4.0/). 